\title{
Imprinting and splicing join together
}

\author{
A gene thought to be involved in RNA splicing, and which is imprinted in mice, may play an important part in \\ Prader-Willi syndrome
}

THE phenomenon of genetic imprinting holds a particular fascination for biologists. By what mechanism, and for what purpose, should some genes (which ones?) be expressed only from the chromosome inherited from the mother, and others only from the paternal chromosome? The best known examples in humans are the widely contrasting phenotypes of the Prader-Willi and Angelman syndromes, both of which are typically caused by deletions of the same portion of the long arm of chromosome 15 (15q11-q13). Patients with PraderWilli syndrome (PWS) (who have either a paternal deletion or two copies of the mother's chromosome 15$)^{1}$ suffer from obesity and assorted developmental defects, whereas children with Angelman syndrome (AS) (with a maternal deletion or paternal uniparental disomy $)^{2}$ are mentally retarded with puppet-like movements, and are prone to seizures.

It is highly likely that a number of imprinted genes contribute to the two syndromes, with PWS, for example, resulting from the paternal loss of a maternally imprinted gene(s). In an effort to define those genes, work has progressed on two main fronts - characterizing rare affected families with unusual deletions which may sublocate the critical regions responsible for the two disorders ${ }^{3,4}$, and transposing this knowledge into a physical map of the region ${ }^{5}$. The upshot of these studies has been that the genes involved in PSW seem to lie closer to the centromere of chromosome 15 than those that make up the AS region, being spread over one megabase (Mb) or more of DNA, whereas the AS critical region is somewhat shorter. But so far the only known gene that maps to either interval is that for the $\gamma$-aminobutyric acid receptor $\mathrm{B} 3$, which lies in the AS interval.

In two papers in this month's Nature

Also in this month's Nature Genetics: three reports on the linkage of earlyonset familial Alzheimer's disease to chromosome 14; the role of mitochondrial DNA deletions in the brain in ageing; repetitive sequences and a PMP-22 mutation in Charcot-MarieTooth disease; chromosome fragmentation using telomeres for genome analysis; and the effects of trinucleotide-repeat expansion in Kennedy's disease.
Genetics, the groups of Uta Francke and Stuart Leff at Stanford, and Neal Copeland and Nancy Jenkins at the National Cancer Institute, show that a newly discovered imprinted gene in mice, whose product is implicated in messenger RNA processing, maps to the critical genomic region involved in $\mathrm{PWS}^{7,8}$. And in an accompanying paper, Bruce Cattanach and colleagues show that this imprinted gene is not expressed in a mouse model for PWS that they have constructed ${ }^{9}$.

The gene studied by these workers, $S N R P N$, encodes the small nuclear ribonucleoprotein polypeptide $\mathrm{N}(\mathrm{SmN})$. $\mathrm{SmN}$ is a component of the small nuclear ribonucleoprotein particles (SnRNPs) found in spliceosomes, which catalyse the splicing and processing of mRNA. SnRNPs are composed of one of five small nuclear RNAs (U1, U2, U4, U5 and U6) and a number of associated polypeptides. Some, such as SnRNP B, are ubiquitously expressed, but others, including the closely related $\mathrm{SmN}$, are tissue-specific. SmN is found predominantly in the brain and central neurons, and as such proteins are known to interact with mRNA, it is tempting to predict a role for $\mathrm{SmN}$ in the tissuespecific control of RNA splicing. Özçelick et al. ${ }^{8}$ cloned the $\mathrm{SmN}$ gene and mapped it precisely on chromosome 15 by determining the presence or absence of SNRPN in DNA from patients with deletions of the PWS/AS region. Every PWS patient with a chromosomal deletion was also missing one copy of $S N R P N$, including two PWS patients with partial, overlapping deletions.

These results firmly place $S N R P N$ in the PWS critical region on chromosome $15 q 12$ - the first known gene to be so assigned. The significance of this result is strengthened by the accompanying work, which shows that the murine homologue, Snrpn, is maternally imprinted (expressed exclusively from the paternal allele $)^{7}$. Leff $e t$ al. mapped the Snrpn gene to the central portion of mouse chromosome 7 , which is syntenically conserved with human chromosome 15g11-13. Next, using an imprinting assay ${ }^{10}$ that distinguishes between the transcripts from two alleles in a cross between Mus musculus and Mus spretus, they could show that in brain RNA only the male-derived Snrpn transcript is detected. The maternal imprinting of Snrpn in mice does not necessarily mean that the human SNRPN gene is imprinted as well, but as at least one known imprinted murine gene, H19, has been shown to be monoallelically expressed in humans ${ }^{11}$, it is a legitimate proposal.

The putative role for $S N R P N$ in PWS is further supported by work from Cattanach and colleagues 9 , who have created a mouse model for the disease in which mice possess two maternally derived copies of the central portion of chromosome 7 . These mice fail to thrive and suffer early postnatal lethality, which may correspond to the early feeding difficulties of PWS infants. No Snrpn message could be detected in the brains of mice with the maternal duplication shortly after birth, whereas normally the transcript is very abundant. In contrast, mice with a paternal duplication of a larger region from chromosome 7 were much healthier and without serious abnormality, although their thin, frail bones could be taken as a sign of an AS-like phenotype.

Could a lack of $S N R P N$ expression contribute to PWS? One possibility is that $\mathrm{SmN}$ normally regulates the splicing of a number of neural-specific genes which might then be affected in PWS. If a role for $\mathrm{SmN}$ is borne out, it would be one of the first examples in which a gene product involved in the DNA $\rightarrow$ RNA $\rightarrow$ protein pathway (the 'central dogma' of molecular biology) has been found. Such a possibility has been aired by David Page and colleagues, who have suggested that the ribosomal S4 proteins encoded by genes on the $\mathrm{X}$ and $\mathrm{Y}$ chromosomes may be involved in the Turner's syndrome phenotype ${ }^{12}$.

Kevin Davies

Kevin Davies is Editor of Nature Genetics.

1. Nicholls, R. D. et al. Nature 342, 281-285 (1989).

2. Malcolm, S. et al. Lancet 337, 694-697 (1991)

3. Hamabe, J. et al. Am. J. med. Genet. 41, 64-68 (1991).

4. Wagstaff, J. et al. Nature Genet. 1, 291-294 (1992).

5. Kuwano, A. et al. Hum. molec. Genet 1, 417-425 (1992).

6. Wagstaff, J. et al. Am. J. hum. Genet. 49, 330-337 (1990)

7. Leff, S. E. et al. Nature Genet. 2, 265-269 (1992).

8. Özçelick, T. et al. Nature Genet. 2, 265-269 (1992).

9. Cattanach, B. M. et al. Nature Genet. 2, 270-274 (1992).

10. Zhang, Y. \& Tycko, B. Nature Genet. 1, $40-44$ (1992). 11. Bartolemei, M. S., Zemel, S. \& Tilghman, S. M. Nature 351, 153-155 (1991)

12. Fisher, E. M. C. et al. Cell. 63, 1205-1218 (1991). 